\title{
Deformation of Combined Retaining Structure in Geological Environment
}

\author{
Yu Wang ${ }^{1,2}$, Yongyu $\mathrm{Li}^{1 *}$, Tianrong Huang ${ }^{1}$, Shihua Wang ${ }^{1}$, Zongying Shu ${ }^{1}$ \\ ${ }^{1}$ Shanghai Urban Construction Vocational College, Shanghai, 200438, China \\ ${ }^{2}$ Shanghai Institute of Technology, Shanghai, 201418, China
}

\begin{abstract}
As a new type of sliding support structure, composite support structure has excellent performance. It is a structure in which two rows of reinforced concrete piles are placed in an appropriate position and the front pile head is connected with the back pile body by a rigid beam. It will form a double row spatial structure, similar to the seating. h-type anti-slide pile can save (or even do not need) anchoring components, form a double-row pile supporting structure system, and achieve good supporting performance. By adjusting the position of tie - beam, the new type anti slide pile has wider universality and applicability. We can make assumptions in the actual calculation.h - type anti - slide pile has strong anti - overturning ability. The compressive strength of the front pile and the tensile strength of the back pile can form a pair of effective anti-overturning bending moments, and the rigid joints also improve the anti-overturning ability.
\end{abstract}

\section{Introduction}

In Our country, the mountainous area is widely distributed, the road traffic construction and other infrastructure projects often encounter this geological situation. Especially in the western region, geological conditions are complex. Such landslides are frequently encountered in our projects, and the thrust force of the landslide is greater than $2000 \mathrm{kN} / \mathrm{m}$. We mainly use large pile and prestressed pile to resist such large thrust landslide. However, both of these measures have some disadvantages.

The bending resistance of common pile is limited, the horizontal displacement is difficult to control, and the construction surface is small. Therefore, for some large landslides, ordinary piles are difficult to meet the requirements ${ }^{[1][2]}$. Ordinary large pile section (e.g., $3 \mathrm{~m} \times 5 \mathrm{~m}$ ) will interfere with the slope during the excavation process, which is not conducive to the stability of the slope and easily leads to the extension of the construction period. In addition, its skid resistance capacity is limited, so the pile spacing should not be too large to resist the large landslide thrust, which will lead to the increase of cost.

As the pressure pile above anchor cable, the tension of anchor pile can improve the stress condition of pile body and reduce the cross section size of pile body appropriately. However, engineering practice found that the structure was somewhat at risk during the year. Its main disadvantages are anchor cable corrosion and relaxation. The long service life of the bolt has not been verified, and its durability and reliability are the important defects of the bolt structure, which makes the service area of the bolt structure smaller and smaller. With this in mind, a more durable, more reliable, and suitably sized anti-slide pile structure should be considered to resist high-thrust landslide.

\section{Analysis of mechanism and feature for $h$ type of anti-sliding piles}

In China, as a new type of anti-sliding support structure, the door-to-door anti-sliding pile has the advantages of large lateral stiffness, strong anti-sliding force, good construction stability and simple construction. We have applied it preliminarily and obtained good results. The portal type anti-slide pile does not have internal support (anchor), so the anti-slide pile construction can be carried out by taking into account the interaction between pile and soil, through the overall stiffness and three-dimensional effect, so as to maintain the stability of the slope and control the deformation. (See Figure1)

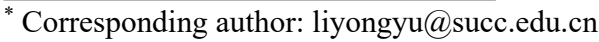




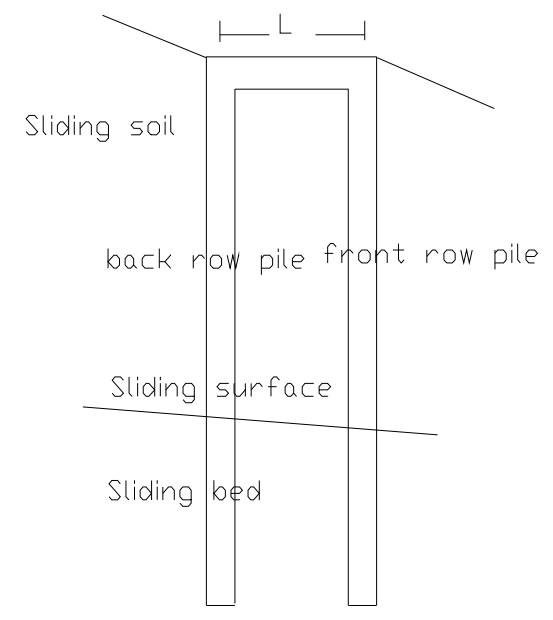

Fig 1. Schematic diagram of portal anti-sliding piles

According to the basic principle and practical engineering requirements, a new type of anti-slide pile structure, h-type anti-slide pile, is proposed based on the previous research. It is a structure in which two rows of reinforced concrete piles are placed in an appropriate position and the front pile head is connected with the back pile body by a rigid beam. It will form a double row spatial structure, similar to the seating.

The essence is a kind of door type anti-slide pile based on innovative form. Due to the existence of reinforced concrete tie beam, H-type anti-slide pile can save (or even do not need) anchorage members, forming a double-row pile supporting structure system, so as to achieve good supporting performance. Because the position of tie beam can be adjusted, the new type anti-slide pile has wider universality and applicability (As shown in Figure 2). In the actual calculation, we make the following assumptions.

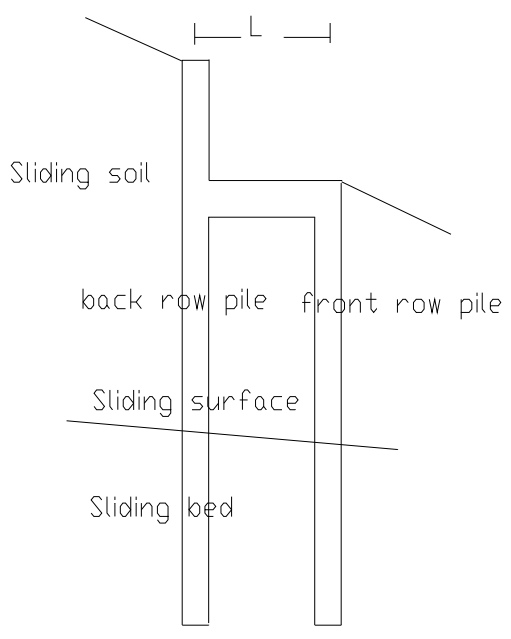

Fig 2. h type of anti-sliding piles

1) In the design of tie beam, the front pile and the back pile are connected as nodes, and the Angle of connection point remains unchanged.

(2) The distance between piles is far less than the length of piles, so it can be considered that the stiffness of the front pile and the back pile is far less than the tie beam, which can be approximate to the absolute rigid body.

(3) There is no tensile deformation or compression deformation of the beam. The horizontal displacement of both ends of the tie beam is equal.
On this basis, the deformation pattern of H-type antislide pile can be analyzed (as shown in FIG. 3). The structure is controlled by the soil pressure between piles and the binding beam soil and elastic bearing force under the sliding surface. Once the parameters of soil pressure and foundation stiffness are determined, the structural internal forces can be calculated by using the elastic foundation beam theory and structural mechanics method $^{[3][4]}$ (As shown in Figure 4). 


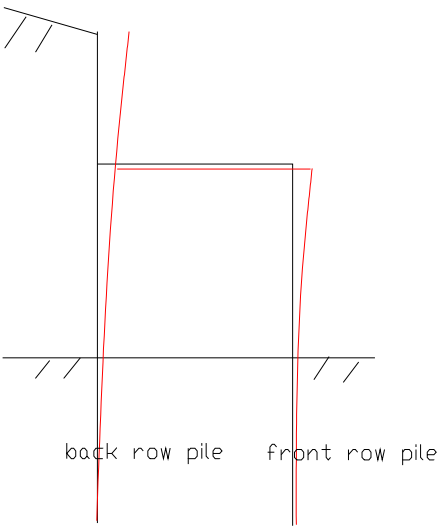

Fig 3. Deformation of $\mathrm{h}$ type of anti-sliding piles

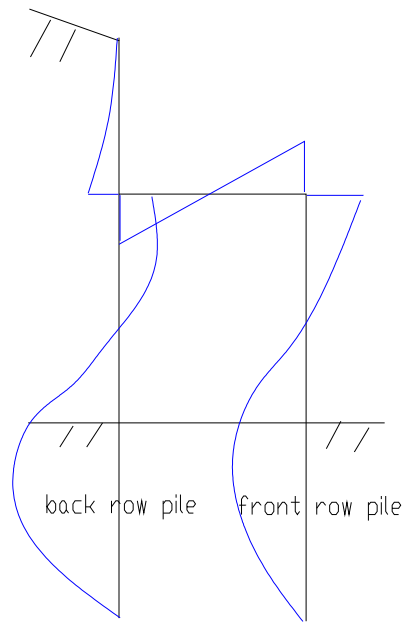

Fig 4. h-type of anti-sliding pile Moment diagram

Through the above analysis, it can be concluded that h-type anti-slide pile has the following characteristics:

(1) As the tie beam cannot rotate freely between the front pile and the back pile, the bending resistance of the structure is greatly improved. At the same time, because of the rigid connection between the tie beam and the pile, the structure has greater horizontal stiffness.

(2) h-type anti-slide pile can automatically adjust the bending moment change according to the bottom foundation support. This structure allows the material to play its full role, reduces the pile diameter, and saves the amount of steel, while the common single pile and anchor pile do not have these characteristics.

(3) h-type anti-slide pile has strong capsizing ability. The compressive strength of the front pile and the tensile strength of the back pile can form a pair of effective antioverturning bending moments, and the rigid joints also improve the anti-overturning ability.

(4) h-type anti-slide pile significantly reduces the maximum negative bending moment of the front pile relative to the gate type anti-slide pile. The reason for this phenomenon is that the construction of Pile $\mathrm{h}$ shortens the length of the front load of the pile. Therefore, the moment of bolt section is under active control.

\section{Influence of cantilever length variation of h-type anti-slide pile}

The mechanical mechanism of H-type anti-slide pile and door type anti-slide pile are basically the same, the main difference lies in the cantilever structure of h-type antislide pile, which makes the force force different from door type anti-slide pile. The cantilever beam can not only bear the thrust of soil, but also play the role of slope and retaining. The function mentioned above should be considered in the design of cantilever beam, and its reasonable size should be calculated to control the bending moment of pile.

Calculation parameters:

(1) geotechnical index: Sliding block is hardening clay, Poisson's ratio $\mu=0.31, \mathrm{c}=20 \mathrm{kpa}, \varphi=42^{\circ}$. $\gamma=20 \mathrm{KN} / \mathrm{m}^{3}, \mathrm{E}=11 \mathrm{Mpa}$. Sliding base is moderately weathered Sandstone, Poisson's ratio $\mu=0.28$ Foundation of coefficient $\mathrm{K}=0.4 \times 10^{6} \mathrm{kpa} / \mathrm{m}, \varphi=68^{\circ}, \gamma=24 \mathrm{KN} / \mathrm{m}^{3}$

(2) piles parameters: $\mathrm{C} 35$ reinforced concrete, $\mathrm{E}=3 \mathrm{e} 4 \mathrm{MPa}$, length of back pile is $27 \mathrm{~m}$, including loading section $19 \mathrm{~m}$, anchoring section $10 \mathrm{~m}$, length of front pile is $21 \mathrm{~m}$, including loading section $12 \mathrm{~m}$, anchoring section $9 \mathrm{~m}$. The distance between the pile is $15.0 \mathrm{~m}$; pile section dimensions $\mathrm{h} \times \mathrm{b}=3.2 \mathrm{~m} \times 2.0 \mathrm{~m}$. 
(3) Under load conditions, the thrust above the sliding surface of landslide thrust can be regarded as uniformly distributed. In the main shaft, the thrust per unit width is $\mathrm{q}=1900 \mathrm{KN} / \mathrm{m}$, surplus resistance before the pile is $\mathrm{q}^{\prime}=790 \mathrm{KN} / \mathrm{m}$
Five different proportions of cantilever lengths were considered: $\mathrm{h}, 0.8 \mathrm{~h}, 0.67 \mathrm{~h}, 0.5 \mathrm{~h}$, (h is the loading length of the rear pile). The top displacement and bending moment of different cantilever lengths are calculated ${ }^{[5]}$ (As shown in table 1 and Figure 5)

Table1. TOP DISPLACEMENT AND MAXIMUM MOMENT OF H TYPE OF ANTI-SLIDING PILES UNDER DIFFERENT CANTILEVER LENGTH

\begin{tabular}{|c|c|c|}
\hline & working condition 1 & $\begin{array}{l}\text { working } \\
\text { condition } 2\end{array}$ \\
\hline Cantilever Length & $\mathrm{H}$ & $0.8 \mathrm{H}$ \\
\hline Top Displacement of Back Pile & $18.16 \mathrm{~mm}$ & $24.42 \mathrm{~mm}$ \\
\hline Top Displacement of front Pile & $28.02 \mathrm{~mm}$ & $22.31 \mathrm{~mm}$ \\
\hline $\begin{array}{l}\text { Maximum Positive Moment of Back } \\
\text { Pile }\end{array}$ & $12907 \mathrm{KN}^{*} \mathrm{~m}$ & $18667 \mathrm{KN}^{*} \mathrm{~m}$ \\
\hline $\begin{array}{l}\text { Maximum Negative Moment of Back } \\
\text { Pile }\end{array}$ & $-63048 \mathrm{KN}^{*} \mathrm{~m}$ & $-52820 \mathrm{KN} * \mathrm{~m}$ \\
\hline $\begin{array}{l}\text { Maximum Positive Moment of Front } \\
\text { Pile }\end{array}$ & $23860 \mathrm{KN}^{*} \mathrm{~m}$ & $25094 \mathrm{KN} * \mathrm{~m}$ \\
\hline \multirow[t]{2}{*}{$\begin{array}{l}\text { Maximum Negative Moment of Front } \\
\text { Pile }\end{array}$} & $-33119 \mathrm{KN}^{*} \mathrm{~m}$ & $-35131 \mathrm{KN} * \mathrm{~m}$ \\
\hline & $\begin{array}{l}\text { working } \\
\text { condition } 3\end{array}$ & $\begin{array}{c}\text { working } \\
\text { condition } 4\end{array}$ \\
\hline Cantilever Length & $0.67 \mathrm{H}$ & $0.5 \mathrm{H}$ \\
\hline Top Displacement of Back Pile & $30.27 \mathrm{~mm}$ & $38.86 \mathrm{~mm}$ \\
\hline Top Displacement of front Pile & $19.85 \mathrm{~mm}$ & $18.37 \mathrm{~mm}$ \\
\hline $\begin{array}{l}\text { Maximum Positive Moment of Back } \\
\text { Pile }\end{array}$ & $23178 \mathrm{KN}^{*} \mathrm{~m}$ & $29027 \mathrm{KN}^{*} \mathrm{~m}$ \\
\hline $\begin{array}{l}\text { Maximum Negative Moment of Back } \\
\text { Pile }\end{array}$ & $-44496 \mathrm{KN}^{*} \mathrm{~m}$ & $-33751 \mathrm{KN}^{*} \mathrm{~m}$ \\
\hline $\begin{array}{l}\text { Maximum Positive Moment of Front } \\
\text { Pile }\end{array}$ & $25913 \mathrm{KN}^{*} \mathrm{~m}$ & $27398 \mathrm{KN}^{*} \mathrm{~m}$ \\
\hline $\begin{array}{l}\text { Maximum Negative Moment of Front } \\
\text { Pile }\end{array}$ & $-36557 \mathrm{KN}^{*} \mathrm{~m}$ & $-39240 \mathrm{KN} * \mathrm{~m}$ \\
\hline
\end{tabular}

The calculation results show that the cantilever length has an influence on the displacement of H-type pile, especially on the displacement of h-type pile top. Obviously, with the change of cantilever length, the displacement trend of the top of the front pile and the back pile is opposite.In the structural design, it is suggested that the cantilever length should not exceed $0.5 \mathrm{~h}$, otherwise it is difficult to control the position shift of Pile H.FIG. 1 shows the comparison diagram of displacement of front and rear pile tops under different cantilever lengths.

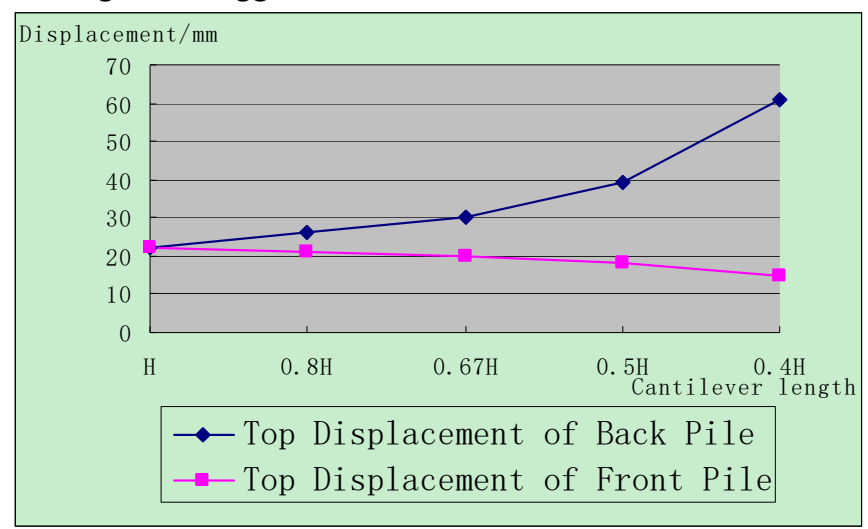

Fig 5. Top Displacement of Back pile and Front pile

At the same time, it also has a significant influence on the length of cantilever beam. Study on positive and negative maximum bending moments of front and rear piles. The maximum positive moment of the rear pile increases rapidly with the increase of the length of the cantilever beam, and the maximum negative moment decreases first and then increases. The maximum positive moment and maximum negative moment of the front pile increase slowly with the increase of the length of the cantilever beam (As shown in FIG. 6). For the design of 
H-type anti-slide pile structure, the control of the absolute value of positive and negative bending moments is very important. According to the above laws, when the cantilever length is $0.5 \mathrm{~h}-0.67 \mathrm{~h}$, the maximum bending moment is relatively small, which is conducive to the optimization of structural design.

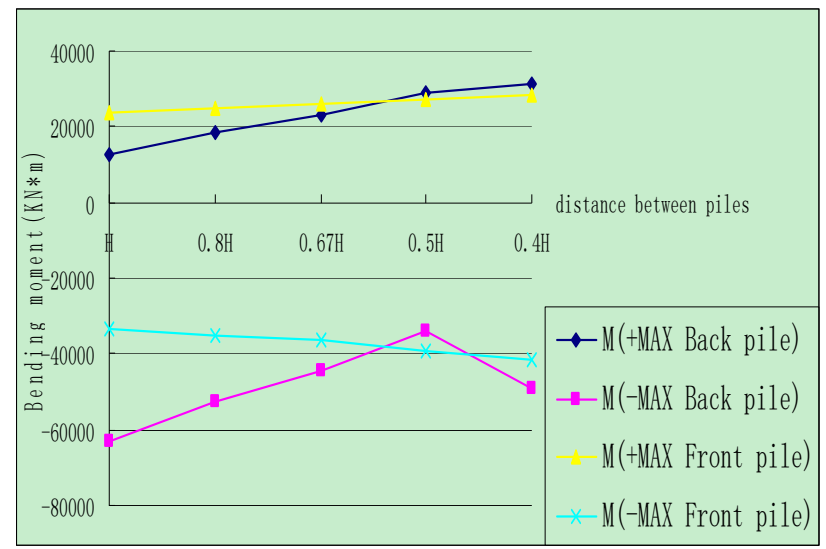

Fig 6. Maximum Positive And Negative Moment for Back pile and Front pile in different conditions

\section{Conclusion}

h-type anti-slide pile can automatically adjust the structural force to adapt to complex load conditions. Ordinary pile is a statically determinate structure without this characteristic. For h-type anti-slide pile, because the rigid tie-beam connects the front pile and the back pile as a whole, it becomes a kind of statically indecisive structure, which makes the displacement, internal force, bending moment and shear force obviously decrease

By replacing anchor pile with h-type anti-slide pile, overlapping construction can be avoided and the cost can be reduced by $5 \%$. The application of h-type anti-slide pile in some engineering parts where the bolt can not be used will show its superiority. Preliminary estimate: using the structure to resist the same landslide thrust, the maximum bending moment is reduced by $60 \%$ compared with ordinary anti-slide pile. At the same time, the stress performance is greatly improved. Therefore, h-type antislide pile has high application value and development potential.

\section{References}

1. DAI Zi-hang,. Numerical solution of piles under lateral load of trapezoid-distribution by parameter method[J]. Chinese Journal of Rock Mechanics and Engineering,2004, 23(15):2632-2638.(in Chinese)

2. Lzmon C: program documentation[J].Journal of the Geotechnical Engineering, ASCE, 1977, 103(4): 287 299

3. ZHENG Gang. Analysis of double-row piles in consideration of the pile-soil interaction[J], Journal of Building Structure,2004,25(1):99-106. (in Chinese). 